\title{
MODELING OF A TURBOFAN ENGINE WITH ICE CRYSTAL INGESTION IN THE NASA PROPULSION SYSTEM LABORATORY
}

\author{
Joseph P. Veres, Philip C. E. Jorgenson, Scott M. Jones, Samaun Nili \\ NASA Glenn Research Center \\ Cleveland, Ohio, USA
}

\section{ABSTRACT}

The main focus of this study is to apply a computational tool for the flow analysis of the turbine engine that has been tested with ice crystal ingestion in the Propulsion Systems Laboratory (PSL) at NASA Glenn Research Center. The PSL has been used to test a highly instrumented Honeywell ALF502R-5A (LF11) turbofan engine at simulated altitude operating conditions. Test data analysis with an engine cycle code and a compressor flow code was conducted to determine the values of key icing parameters, that can indicate the risk of ice accretion, which can lead to engine rollback (un-commanded loss of engine thrust). The full engine aerothermodynamic performance was modeled with the Honeywell Customer Deck specifically created for the ALF502R-5A engine. The mean-line compressor flow analysis code, which includes a code that models the state of the ice crystal, was used to model the air flow through the fan-core and low pressure compressor. The results of the compressor flow analyses included calculations of the ice-water flow rate to air flow rate ratio $(I W A R)$, the local static wet bulb temperature, and the particle melt ratio throughout the flow field. It was found that the assumed particle size had a large effect on the particle melt ratio, and on the local wet bulb temperature. In this study the particle size was varied parametrically to produce a non-zero calculated melt ratio in the exit guide vane (EGV) region of the low pressure compressor (LPC) for the data points that experienced a growth of blockage there, and a subsequent engine called rollback (CRB). At data points where the engine experienced a CRB having the lowest wet bulb temperature of $492 \mathrm{R}$ at the EGV trailing edge, the smallest particle size that produced a non-zero melt ratio (between $3 \%-4 \%$ ) was on the order of $1 \mu \mathrm{m}$. This value of melt ratio was utilized as the target for all other subsequent data points analyzed, while the particle size was varied from $1 \mu \mathrm{m}-9.5 \mu \mathrm{m}$ to achieve the target melt ratio. For data points that did not experience a CRB which had static wet bulb temperatures in the EGV region below $492 \mathrm{R}$, a non-zero melt ratio could not be achieved even with a $1 \mu \mathrm{m}$ ice
\end{abstract}

particle size. The highest value of static wet bulb temperature for data points that experienced engine $\mathrm{CRB}$ was $498 \mathrm{R}$ with a particle size of $9.5 \mu \mathrm{m}$. Based on this study of the LF11 engine test data, the range of static wet bulb temperature at the EGV exit for engine CRB was in the narrow range of $492 \mathrm{R}$ - $498 \mathrm{R}$, while the minimum value of IWAR was 0.002 . The rate of blockage growth due to ice accretion and boundary layer growth was estimated by scaling from a known blockage growth rate that was determined in a previous study. These results obtained from the LF11 engine analysis formed the basis of a unique "icing wedge."

\section{NOMENCLATURE}

$\begin{array}{ll}\text { CD } & \text { Customer Deck } \\ \text { COMDES } & \text { Compressor flow analysis code } \\ \text { CRB } & \text { Engine Called Rollback } \\ \text { EGV } & \text { Exit Guide Vane } \\ \text { HPC } & \text { High Pressure Compressor } \\ \text { HPT } & \text { High Pressure Turbine } \\ \text { IGV } & \text { Inlet Guide Vane } \\ \text { ISA } & \text { International Standard Atmosphere } \\ \text { IWAR } & \text { Ice-Water Flow Rate to Air Flow Rate Ratio } \\ \text { LPC } & \text { Low Pressure Compressor (supercharger) } \\ \text { MELT } & \text { Ice particle thermodynamic state model } \\ \text { PSL } & \text { Propulsion Systems Laboratory } \\ \text { PT2 } & \text { LPC Exit Total Pressure } \\ \text { PT3 } & \text { HPC Exit Total Pressure } \\ \text { R } & \text { Rankine } \\ \text { TT2 } & \text { LPC Exit Total Temperature } \\ \text { TT3 } & \text { HPC Exit Total Temperature } \\ \text { TT45 } & \text { HPT Exit Total Temperature } \\ \text { Twbs } & \text { Static wet bulb temperature } \\ \text { TWC } & \text { Total Water Content } \\ \mu m & \text { Micron }\end{array}$




\section{INTRODUCTION}

There have been numerous reported engine icing events [1] that have occurred on commercial airlines (Figure 1) during flight through clouds with high ice water content. These events have been attributed to ice crystal ingestion and subsequent ice buildup. The total number of engine icing events per year appears to be increasing since 2002 [2].

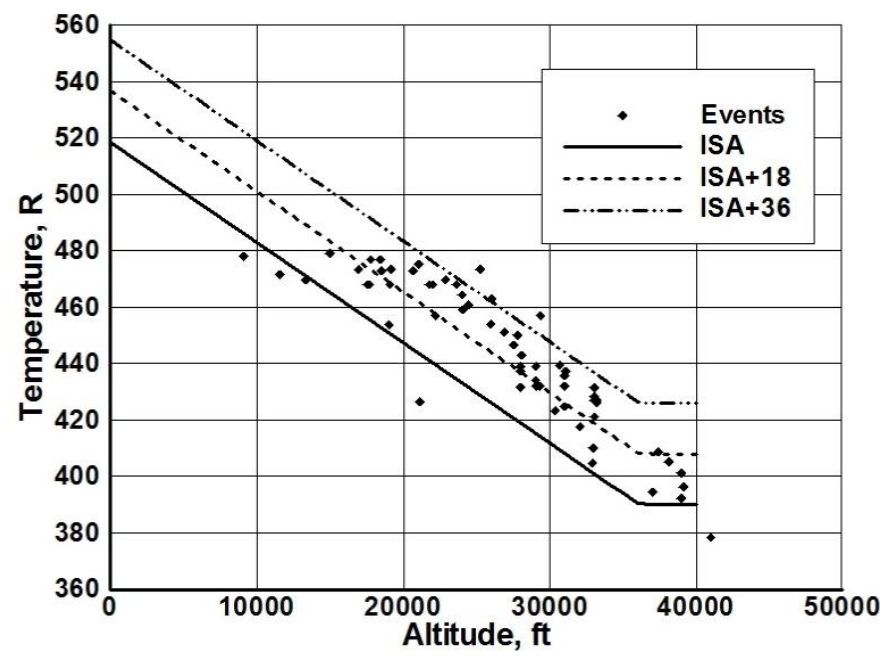

Figure 1: Reported engine icing events. The engine events occurred at altitudes between $10 \mathrm{~K}$ and $40 \mathrm{~K}$ feet and at temperatures between ISA and ISA+36 R.

These engine events have taken place at high altitudes and have been attributed to ice crystal ingestion, and are thought to result in accretion on the stationary parts of the low pressure compressor. As ice crystals are ingested into the fan and low pressure compression system, the air static temperature typically increases and a portion of the ice crystals melts due to the warmer air. This allows the ice-water mixture to stick and/or accrete upon impacting the metal surfaces of the compressor components. It is hypothesized that this allows the ice-water mixture to cover the metal surfaces of the compressor stationary components which leads to ice accretion through evaporative cooling. The accreted ice causes a blockage which subsequently results in the deterioration in performance of the compressor and engine. One or more of the following modes of failure can occur: un-commanded loss of thrust control (engine rollback), compressor surge or stall, ice shedding resulting in structural damage to the downstream compressor blades, and possible combustor flameout.

The unmodified ALF502R-5A serial LF01 is commercial turbofan engine which has previously experienced icing events during operation in a high altitude ice crystal environment and has been tested in the Propulsion Systems Laboratory (PSL) altitude test facility at NASA Glenn Research Center [3,4]. A highly instrumented version of this turbine engine has been tested in the PSL (serial LF11 shown in Figure 2), as a continuation of the testing that was performed in 2013 on the
ALF502R-5A serial LF01 [5-7]. Previous operating points tested in the LF01 engine were duplicated and confirmed for repeatability in the LF11.

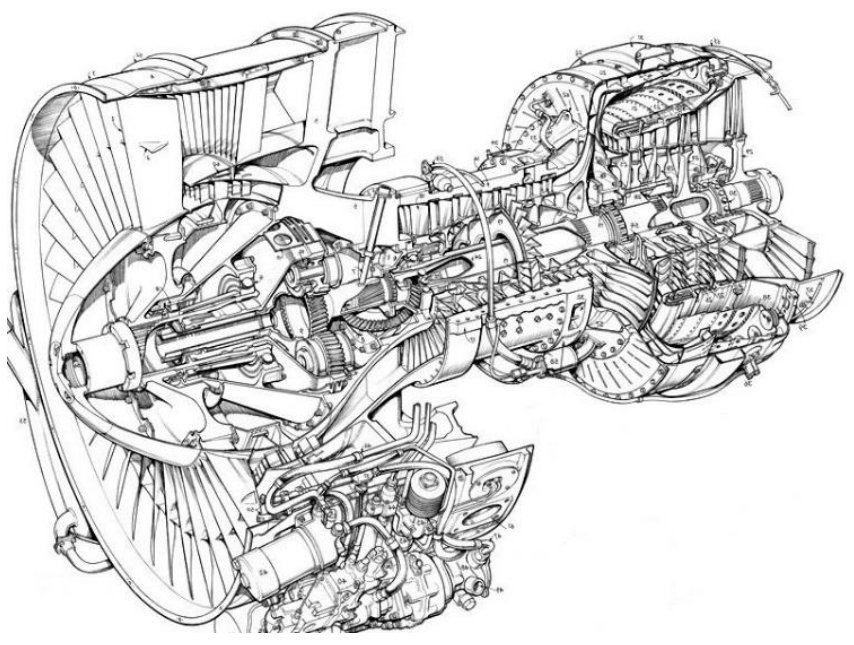

Figure 2: ALF502R-5A Turbofan Engine (Courtesy Honeywell Engines).

In this engine it has been confirmed by video cameras [5] that the accretion occurred at the exit guide vane (EGV; tandem stator 1 and stator 2) of the low pressure compressor (LPC), illustrated in Figure 3.

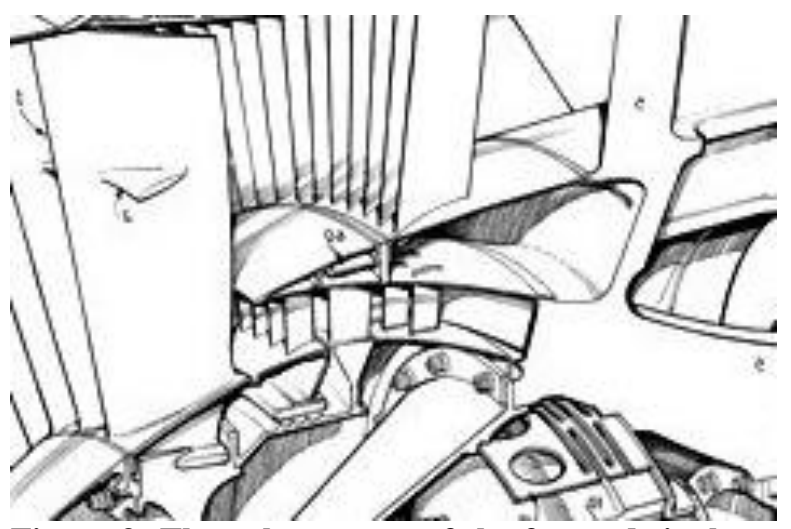

Figure 3: The enlargement of the fan and single-stage LPC illustrating the IGV and the tandem stator; EGV stator 1 and EGV stator 2.

The focus of the previous research [8] was to apply an engine icing computational tool to simulate the flow through a turbofan engine and assess the risk of ice accretion, with the assumption of an identical ice particle size for all data points that were analyzed. That research resulted in determining values for key icing parameters that indicate the risk of whether ice accretion will occur. These parameters are the local static wet bulb temperature, melt ratio, and the ice-water flow rate to air-flow rate ratio $(I W A R)$. The minimum value of IWAR was determined to be on the order of 0.002 for there to be a risk of ice accretion. Note that the value of IWAR strongly depends on the accurate 
measurement of TWC [6]. In that study [8] an initial ice particle size of $5 \mu \mathrm{m}$ was assumed, due to no available particle breakup data, or model and from previous studies [9]. Likewise the resulting computed melt ratios in the previous study were in the range of $0 \%-15 \%$. Approximately $60 \%$ of the data points analyzed had calculated melt ratios greater than zero at the region of the EGV where ice accretion was observed, while $40 \%$ of the engine operating points had ice particles with no liquid component (zero melt ratio), even though the engine experienced a CRB. In retrospect, those calculated static wet bulb temperatures may have been unrealistic, particularly at the low end of the scale (Reference 8, Figure 17b). It is generally believed that as particles without a liquid component come in contact with the dry compressor surfaces, the ice particle would break-up but not accrete. Therefore, the main focus of the current study is to modify the ice particle phase change computations by varying the particle size input to obtain a partially melted particle (with non-zero melt ratio), for all the operating points that experienced engine CRB. This was done by iteratively varying the initial size of the ice particle, and the details will be discussed in a subsequent section.

\section{ENGINE ICING ANALYSIS; COMPUTATIONAL TOOLS}

A system of computational codes [8-14] has been developed with the capability to analyze the performance of a turbine engine, with the added capability to simulate the ingestion of ice crystals. The codes can be used to evaluate the susceptibility of turbine engines to the risk of ice accretion. The computational tool is comprised of an engine system thermodynamic cycle code (Honeywell Customer Deck, CD), a compressor flow analysis code (COMDES [14]) with additional capabilities (Figure 4). The compressor flow code includes a fluid properties code that determines the effects of water vapor, and an ice particle code that tracks the thermodynamic state of the particle through the compressor flow field. The thermodynamic cycle code is zero dimensional, while the compressor flow code is onedimensional. There is an exchange of boundary conditions between the cycle code and the compressor code.

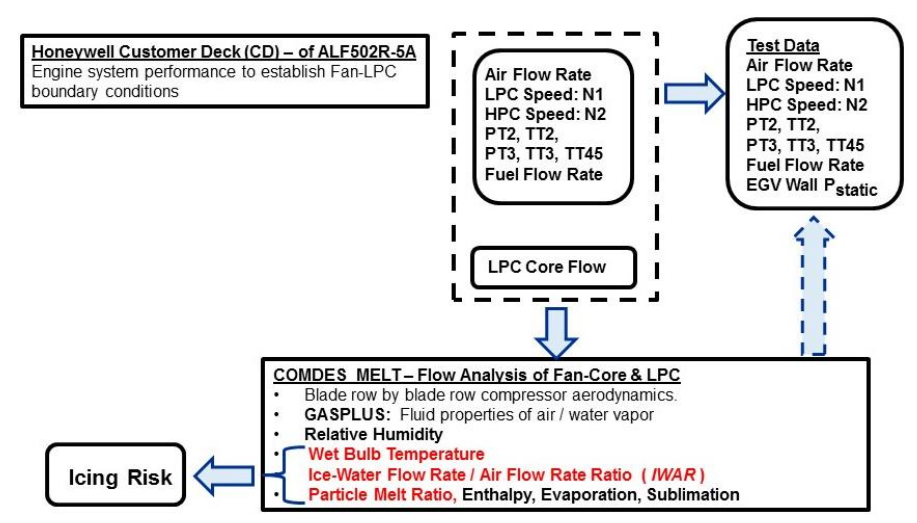

Figure 4: Computational process for the flow analysis of the Honeywell engine's fan-core, LPC and strut. The boundary conditions from the $\mathrm{CD}$ are passed to the compressor flow code to obtain a full analysis of the flow field.
The mixed-fidelity computational codes provide details of the flow conditions within each blade row of the fan and low pressure compression system (LPC). The block diagram in Figure 4 illustrates the process by which the boundary condition data is transferred between the CD system model and the meanline flow analysis code.

The CD thermodynamic system modeling code input values include the altitude, flight Mach number, rotational speed of the fan-core / LPC, and the ambient air (static) temperature. The CD model output results include the aerothermodynamic performance of the major engine components are illustrated in Figure 5.

\section{ENGINE SYSTEM MODEL (CUSTOMER DECK)}

The CD code provides the overall component-level performance and flow conditions, pressures, and temperatures, air and fuel mass flow rates, for the major engine components, as shown in Figure 5. In the CD model, the fan is divided into two distinct regions, the fan-tip which models the flow through the bypass, and the fan-core, which includes the low pressure compressor (supercharger). The CD system modeling code utilizes engine component characteristic maps for each major engine component. Thus, it does not have adequate fidelity to provide the flow conditions within the stages or at the rotor blade and stator vane leading and trailing edges. The main purpose of utilizing the $\mathrm{CD}$ engine system model was to provide the mass flow rate of air into the engine core.

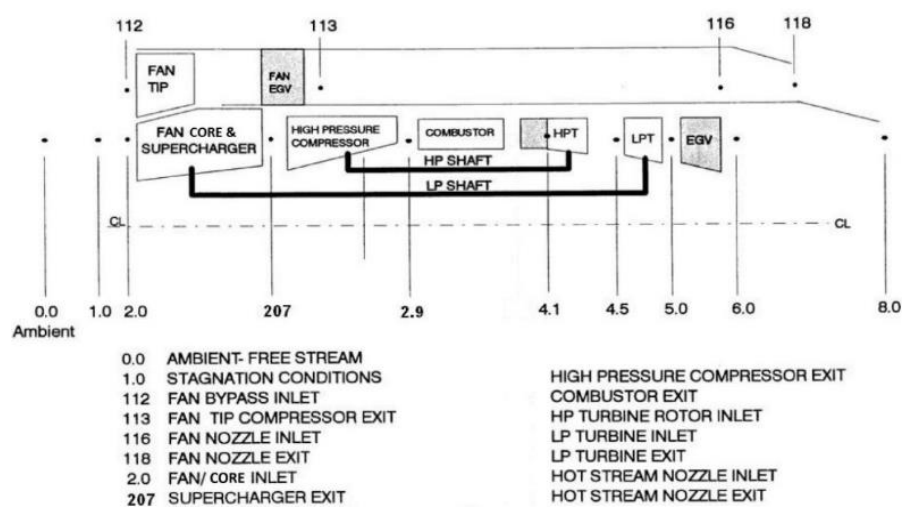

Figure 5: The engine block diagram of the two spool turbofan engine, as modeled in the Honeywell Customer Deck (CD).

\section{SPREADSHEET}

A spreadsheet was created in order to enable a rapid means of providing the input parameters into the CD system modeling code. The spreadsheet then executes the CD, and subsequently passes boundary conditions to the COMDES flow code, and ultimately executing it as well. The total computational time for the spreadsheet, $\mathrm{CD}$, and COMDES flow analysis codes is less than 1 second of wall-clock time. 


\section{COMPRESSOR FLOW ANALYSIS CODE}

The COMDES flow code is a mean-line compressor flow analysis code that computes the velocity, pressure, temperature, and flow angles at the leading edge and trailing edge of each blade row, at the hub, mean, and tip sections as well as the overall compressor performance. The code has been modified to include the effects of relative humidity on the fluid properties of air with water vapor.

Additionally, the compressor flow analysis code incorporates a code named MELT [9] to model the thermodynamic state of ice particles, as they pass through the engine inlet, fan-core and low pressure compressor blade rows. Models for sublimation, melting, and evaporation are included in the MELT code, however, currently there are no models within the code for ice accretion, particle breakup, sticking, shedding, or erosion. The compressor code COMDES and MELT have been tightly coupled to exchange fluid dynamic boundary conditions, and enthalpy at the blade leading and trailing edge of each blade row. The MELT code also computes the particle melt ratio, the thermal state and possible change of phase, and the residence time. The specific humidity, the total water content (TWC), and particle diameter are specified at the inlet to the engine. The value for ice particle diameter in this study is assumed to be variable. The total water content (TWC) is specified from the test data taken in the PSL. After the flow conditions through the blade rows have been calculated by COMDES, the static temperatures, pressures, and velocities are passed to MELT to determine the rate of melting, sublimation, and evaporation, and thus, the local ice particle melt ratio in each blade row. This coupled calculation required an iterative exchange of boundary conditions between the COMDES and MELT codes to update he change in fluid properties of the air due to the ice particles, as well as an exchange of enthalpy between the particles and the air.

Figure 6 illustrates a representation of the fan-core and low pressure compressor cross section of the Honeywell ALF502R$5 \mathrm{~A}$ engine that was analyzed with COMDES. Note that a notional streamline is utilized in the compressor flow model that represents the streamline that divides the flow between the fan bypass duct, and the flow entering the core. This Honeywell engine features a heated spinner and a heated fan-core stator row (inlet guide vane - IGV) shown in Figure 6 that are not modeled in COMDES. The fan-core is followed by a single stage LPC having a tandem stator exit guide vane (EGV). The tandem stators in the low pressure compressor stage (exit guide vanes EGV) are also shown in the figure. Note that the compressor model also includes the flow analysis through the duct and the support strut downstream of the EGV.

Figure 7 shows a simplified sketch of the ice particle path through the rotor blades in the relative frame of reference, while the path through the stator vanes is in the absolute frame of reference.

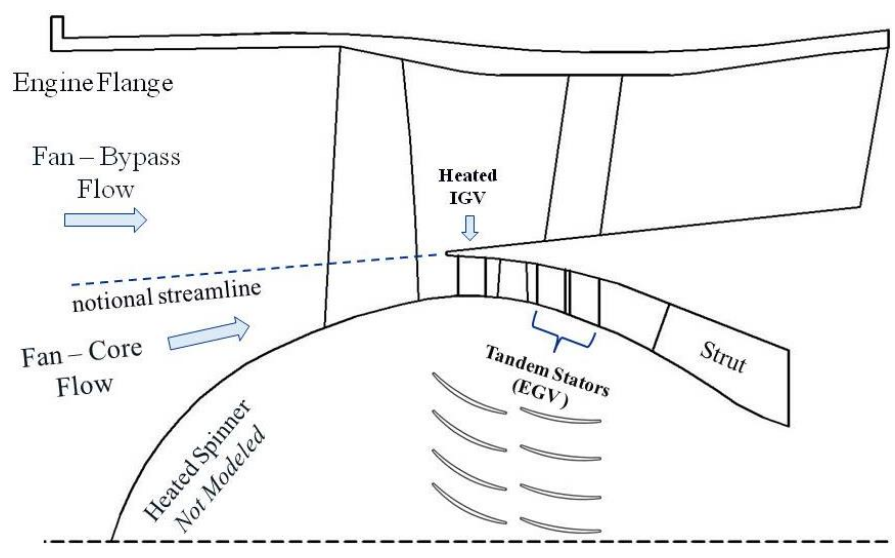

Figure 6: Fan-core and low pressure compressor region of the engine.

The calculations of ice sublimation, melt, and evaporation are performed from the leading to the trailing edge of each rotor and stator, as well as through the axial gap between the blades, as a function of velocity and distance traveled. The distances traveled are assumed to be the chord length of each rotor and stator, as well as the gap between rotor and stator. The amount of water vapor increase due to sublimation and evaporation is added to the local value of specific humidity, thus having an effect on the local relative humidity, and likewise on the local static wet bulb temperature calculation in the compressor code.

In this engine, the most susceptible location where ice forms is suspected to be in the region of the LPC exit guide vane (EGV) tandem stators (stator 1 and stator 2), as illustrated in Figure 7. The presence of ice accretion in that areas as a whole has been observed downstream of the EGV region by video imaging, however there is an unconfirmed possibility that ice could also have formed at other locations.

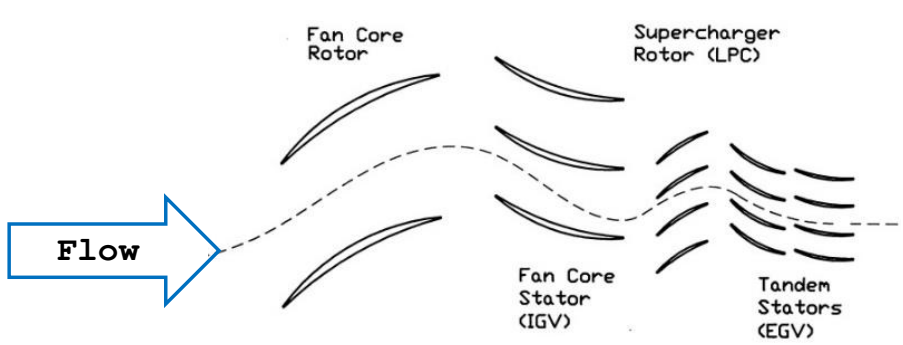

Figure 7: Ice particle path through the inlet, fan-core and low pressure compressor stage, featuring a tandem stator EGV (stator 1 and stator 2).

\section{ICE ACCRETION RISK}

The main focus of this study is to further calibrate the key icing parameters based on a more complete analysis of the LF11 engine test, mainly, through varying the initial size of the ice particle. The icing risk parameters, as identified in previous studies are the wet bulb temperature based on the local value of static air temperature, the ice particle melt ratio, and the value of 
IWAR [7]. IWAR, a dimensionless parameter, is defined by the following equation:

$$
I W A R=\frac{T W C * Q}{m}
$$

where TWC is the total water content in the atmosphere, $Q$ is the air volumetric flow rate, and $m$ is the actual mass flow rate of the air entering the engine. The TWC in PSL simulates the atmosphere, with some radial uniformity characteristics as detailed in [6]. For the PSL data points analyzed in these studies, a $7 \%$ loss of thrust was accepted as the called rollback (CRB) occurrence criterion as a predictor for a full engine rollback. This limit was set to prevent significant ice buildup and blade damage from occurring due to possible ice shedding. This was referred to as a "called rollback" (CRB). Figure 8 illustrates the Escort $[5,6]$ data from a full engine rollback that was reported in a previous study [8].

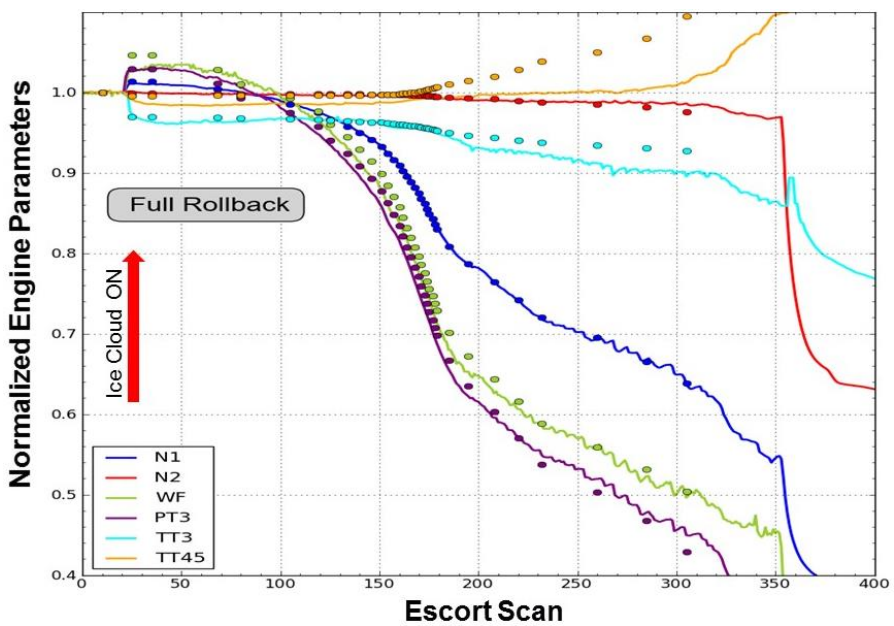

Figure 8: Test data point illustrating the variation of measured engine parameters with the ice cloud on and culminating in a full engine rollback event (Escort data 93).

Note that when the ice cloud is initiated (scan 23), the engine instantly reacts with an increase in fuel flow rate, and an abrupt increase in the fan speed, while the core speed remains essentially constant. As a result, the thrust increases, and the ratio of fan speed to core speed changes in the first few seconds after the ice cloud is initiated. This occurs even before there could possibly be any significant amount of accretion on the compressor surfaces, and is merely due to the heat transfer effects associated with the introduction of ice-water [12] into the air flow. Around scan 50, as ice begins to accrete in the engine, the fan speed, engine thrust, fuel flow rate, and the high pressure compressor exit conditions start to deteriorate.

\section{COMPRESSOR FLOW ANALYSIS OF THE FAN-CORE, LPC, AND STRUT}

The COMDES code was utilized to conduct a complete analysis of the flow through the fan-core, LPC and strut for the 69 data points, see Table 1 listed in the Appendix. The key icing parameters were calculated as part of the flow field solution. Figure 9 illustrates an example of the distribution of calculated static wet bulb temperature (Twbs) and particle melt ratio through the fan-core and LPC for three test data points $(293,320$ and 166). These represent the flow field at the lower limit of Twbs for accretion, maximum accretion (blockage growth rate), and the upper limit of Twbs. These limits were inferred from the analysis results in Table 1, and will be discussed in more detail in the next section. Although the computation included the entire flow field of the inlet, fan-core, LPC, and strut, the targeted region was the main focus of the analyses, since that is where accretion was observed by video imaging during the PSL tests. The focus of the next section will be on the values of the key icing parameters in the targeted area, mainly the EGV tandem stator 2 trailing edge.

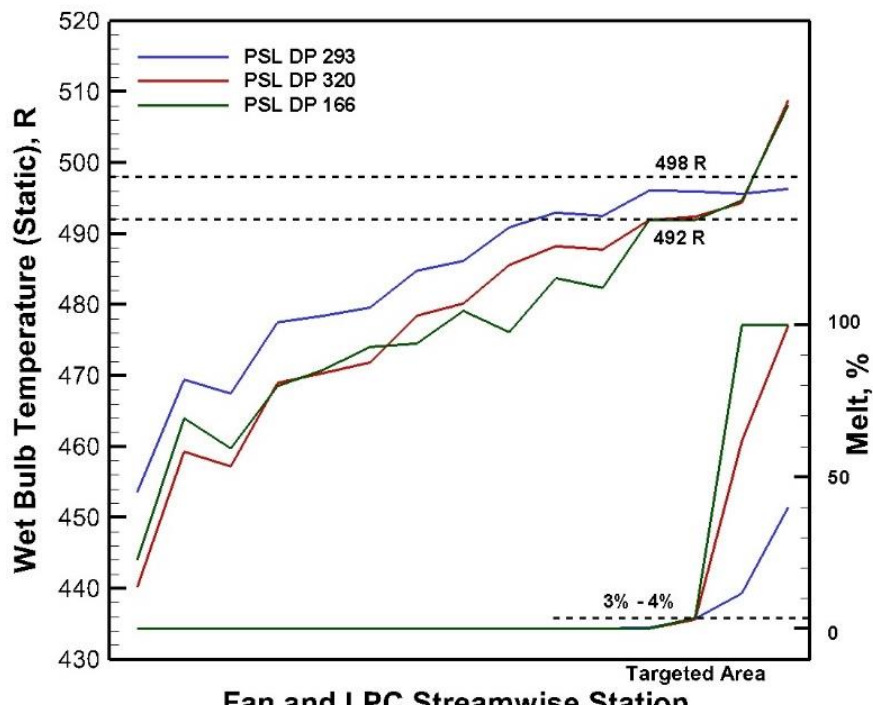

Figure 9: Streamwise distribution of static wet bulb temperature and particle melt ratio through the fan-core and LPC, and support strut.

\section{QUANTIFY KEY PARAMETERS ASSOCIATED WITH ICE ACCRETION AT THE TARGETED AREA}

In this study there were 69 PSL data points taken on LF11 that were analyzed with the compressor flow code, including 19 of the 24 data points from Reference [8], as well as additional LF11 data points which have not been included in that reference. Five of the data points from Reference [8] were low altitude points and are not included in the current study. The test data points analyzed included both engine called rollback and non-rollback data points. The results of the computations are presented in Table 1 in the Appendix, and include the key icing parameters $I W A R$, static wet bulb temperature, and the estimated blockage 
growth rate, at the targeted area of the EGV stator 2 trailing edge. The size of the ice particle refers to the simulated initial size as it enters the engine, and not the measured particle size. The estimated blockage growth rate was based on a calculation of the growth rate of one full rollback data point (Escort 93 [8]) that had a growth rate of $0.0095 \mathrm{~cm} / \mathrm{sec}$. Figure 10 shows the video image of the accreted ice at the EGV stator 2 trailing edge, at Escort scan 92. Note that the ice cloud was turned on at Escort scan 23.

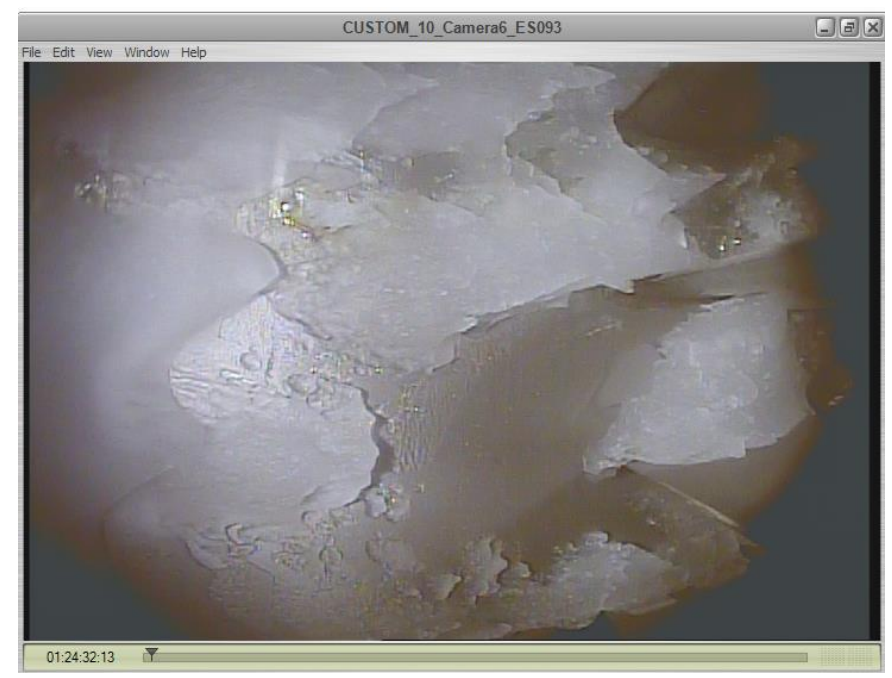

Figure 10: Video image of the accreted ice at the EGV stator 2 trailing edge, at Escort scan 92 after the ice cloud was initiated.

The blockage growth rate is the sum of the physical blockage due to ice accretion, as well as the resulting growth of the boundary layer. The blockage growth rate for the full rollback Escort data point 93 was calculated to be $0.0095 \mathrm{~cm} / \mathrm{sec}$. The assumption made was that the amount of total blockage in the EGV to reach $7 \%$ un-commanded loss of thrust was the same for all data points that were judged to be a called rollback. It was determined that the full rollback point (Escort 93) would have met the criteria for a called rollback at Escort scan 92 after ice cloud was initiated at Escort scan 23. The blockage growth rate was scaled for all the other data points based on the time they required to reach the $7 \%$ loss of engine thrust. This was the criteria that was required to be judged a engine called rollback (CRB).

For the data points that experienced CRB at the low end of the wet bulb temperature range, it was determined that a particle size on the order of $1 \mu \mathrm{m}$ was required to provide a melt ratio on the order of between $3 \%-4 \%$ at the EGV tandem stator trailing edge region. Note that other sources of liquid water may also be present due to the heated spinner and IGV (Figure 6). The calculated melt ratio of between $3 \%-4 \%$ is in addition to those other potential liquid water sources. For each subsequent Escort data point the particle size was determined in order to force the same melt ratio of between $3 \%-4 \%$. This was successfully achieved through data point 328 (see Table 1 in the Appendix). For the last five data points at the bottom of Table 1 it was not possible to attain a non-zero melt ratio even with a $\sim 1 \mu \mathrm{m}$ particle size. However, these data points did not experience a CRB, and thus a zero melt ratio was expected, and likewise the Twbs is well below freezing. These non-rollback points support the understanding that liquid water is required for the occurrence of ice accretion. Therefore this range of melt ratio between $3 \%-4 \%$ was utilized as the guideline for this analysis of all subsequent data points. Using this guideline, the ice particle size was iteratively varied in the compressor flow analysis code, and the compressor blade row by blade row performance was computed, including the distribution of static wet bulb temperature through the fan-core and LPC flow path. Note that the data points listed in Table 1 have been sorted in order of decreasing static wet bulb temperature (Twbs). The prescribed initial value of ice particle size entering the engine inlet was in the range of $9.5 \mu \mathrm{m}$ to $0.835 \mu \mathrm{m}$ in order to attain a melt ratio of between $3 \%$ and $4 \%$. The key icing parameters (static wet bulb temperature, IWAR and blockage growth rate) for a given melt ratio from Table 1 are plotted in Figure 11. These values of key icing parameters were calculated at the EGV (tandem stator trailing edge). The estimated blockage growth rate, IWAR, and the calculated static wet bulb temperature form an "icing wedge" that defines the region of ice accretion risk. As a result of imposing the prescribed melt ratio, the range of Twbs for ice accretion risk has been reduced from the previous study [8] and Table 1 shows the new calculated values. Varying the ice particle size raised the lower threshold limit of Twbs to $492 \mathrm{R}$, yet the upper limit of Twbs for icing risk remained near $498 \mathrm{R}$. Thus the icing wedge which indicates where ice accretion can result has a narrow range of Twbs of only $6 \mathrm{R}$.

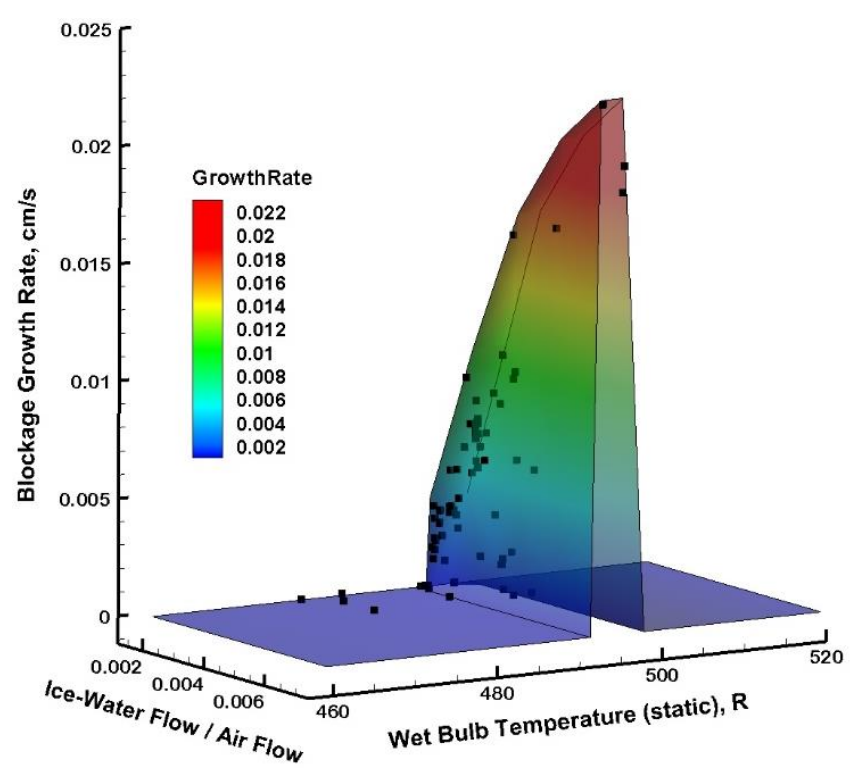

Figure 11: Blockage growth rate versus $I W A R$ and wet bulb temperature, forming the "icing wedge" that defines the region of ice accretion risk. 
Therefore, when the engine operates in an ice cloud environment that results in a Twbs between $492 \mathrm{R}-498 \mathrm{R}$ in the LPC region, the blockage growth rate due to ice accretion and boundary layer growth is determined by the level of IWAR and the amount of time at that operating condition.

The dependence of blockage growth rate as a function of IWAR is illustrated in Figure 12, which is a two-dimensional rotated view of Figure 11. The analysis of the LF11 test data indicates that the lower limit of IWAR in order for un-commanded thrust reduction is on the order of 0.002 . However, data was taken up to a value of 0.007 , which had a calculated blockage growth rate of $0.0226 \mathrm{~cm} / \mathrm{sec}$.

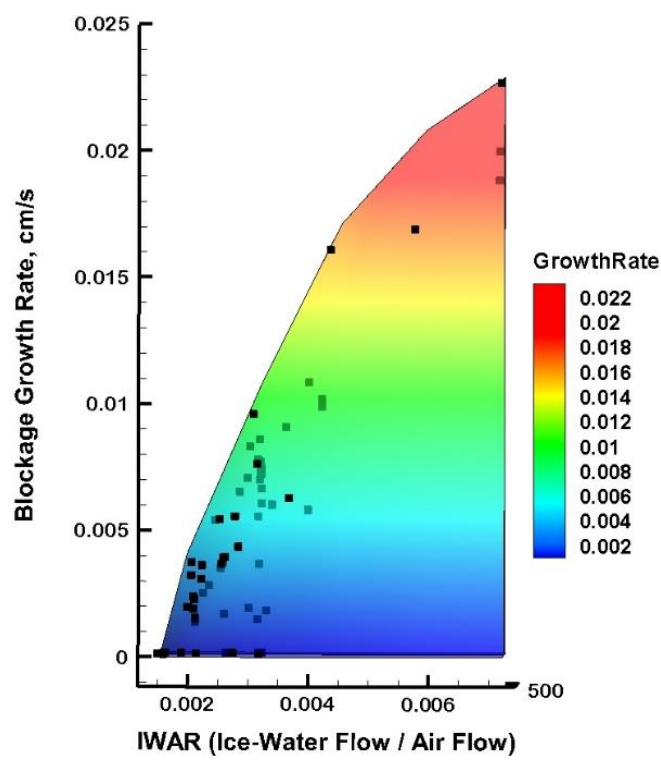

Figure 12: Blockage growth rate as a function of IWAR. Note that the blockage growth rate applies only in the narrow range of Twbs between $492 R$ and $498 R$.

Figure 12 illustrates an upper limit of blockage growth rate as a function of IWAR. However, even though the existence of a lower limit of blockage growth rate at high values of IWAR cannot be deduced from the current data, the blockage growth rate was extrapolated down to zero for illustration purposes. The blockage growth rate only applies if the Twbs is in the range of $492 \mathrm{R}-$ $498 \mathrm{R}$.

The narrow range of Twbs that determines the risk of ice accretion is illustrated in Figure 13, which is a two-dimensional rotated view of Figure 11. The horizontal plane in Figure 13 is slightly tilted for illustrative purposes but represents a blockage growth rate of zero. The highest values of blockage growth rate was determined to be approximately one degree above the lower limit threshold for accretion (492 R). This is a narrower range of Twbs than was previously reported [8], which was based on a limited set of data analyzed, as well as the assumption of a constant particle size of $5 \mu \mathrm{m}$.

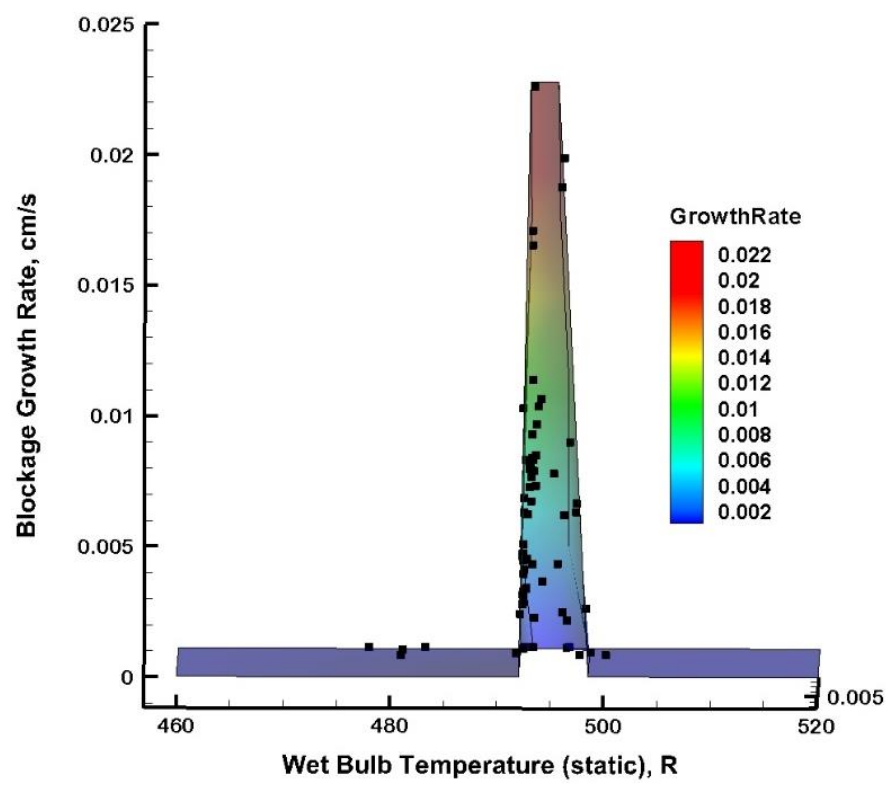

Figure 13: The range of static wet bulb temperature forming the "icing wedge" that defines the region of ice accretion risk (between $492 \mathrm{R}-498 \mathrm{R}$ )

\section{CONCLUSIONS}

The major conclusions from the analysis of the highly instrumented Honeywell ALF502R-5A engine tested in PSL are as follows:

1. The risk of ice accretion is a function of the local static wet bulb temperature as well as the ratio of ice-waterflow-rate to air-flow-rate $(I W A R)$ and the particle melt ratio at the LPC EGV stator 2 trailing edge.

2. Ice accretion at EGV stator 2 trailing edge occurs when the static wet bulb temperature is within the range of $492 \mathrm{R}-498 \mathrm{R}$.

3. The minimum value IWAR for blockage growth at the EGV trailing edge due to ice accretion, and subsequent engine called rollback is on the order of 0.002 .

4. The blockage growth rate is a function of the ice-water flow rate to air flow rate (IWAR) ratio, provided that the static wet bulb temperature lies between $492 \mathrm{R}$ and 498 $\mathrm{R}$. The blockage growth rate was scaled based on the time required to reach the $7 \%$ loss in measured relative engine thrust (called rollback).

5. The melt ratio determined for a risk of ice accretion was calculated to be between $3 \%-4 \%$. This was determined from the analysis of data points that had low values of Twbs at EGV stator 2 trailing edge, and also did not experience called rollback. Even assuming particle size at $1 \mu \mathrm{m}$, it was not possible to attain a non-zero particle melt ratio. 


\section{ACKNOWLEDGMENTS}

This work is supported by the Advanced Air Transport Technology Project in the NASA Advanced Air Vehicles Program, and is in response to the Engine Icing Technical Challenge. We would like to thank Anthony Nerone, manager of the NASA Advanced Aircraft Icing Subproject, for supporting this work. We would also like to acknowledge Ashlie Flegel, Dr. Michael Oliver, Dr. Judith Foss Van Zante, Timothy Bencic, Amy Fagan, Christopher Lynch, Bryan Rosine, Tom Griffin, Queito Thomas, Jonathan Paul Kirkegaard, Dennis Dicki, Paul Lizanich, Steve Pesek, Jonathan Borman, Pamela Poljak, Kent A. Smith, and the PSL technicians and engineers that supported the test and facility development at NASA Glenn Research Center for providing the excellent test data for this engine in the unique altitude test facility with spray bars that successfully simulated ice ingestion testing. We also acknowledge the help and guidance we received from Dr. William B. Wright (Vantage Partners, LLC.) for guidance in providing the MELT code and Dr. Jen-Ching Tsao (Ohio Aerospace Institute) for his insights and analyses. We would also like to thank the managers and engineers at Honeywell Engines for the use of their turbofan engine for testing in the PSL at NASA GRC.

\section{REFERENCES}

[1] Mason, J. G., Chow, P., Fuleki, D. M., "Understanding Ice Crystal Accretion and Shedding Phenomenon in Jet Engines Using a Rig Test," GT2010-22550.

[2] Mason, J. G., Grzych, M., "The Challenges Identifying Weather Associated With Jet Engine Ice Crystal Icing," SAE 2011-380094.

[3] Oliver, M. J., "Validation Ice Crystal Icing Engine Test in the Propulsion Systems Laboratory at NASA Glenn Research Center," AIAA-2014-2898.

[4] Goodwin, R. V., Dischinger, D. G., “Turbofan Ice Crystal Rollback Investigation and Preparations Leading to Inaugural Ice Crystal Engine Test at NASA PSL-3 Test Facility," AIAA 20142895.

[5] Flegel, A. B., Oliver, M. J., "Preliminary Results from a Heavily Instrumented Engine Ice Crystal Icing Test in a Ground Based Altitude Test Facility," AIAA-2016-3894.

[6] Van Zante, J. F., Bencic, T. J., Ratvasky, T. P., "NASA Glenn Propulsion Systems Lab Ice Crystal Cloud Characterization Update 2015," AIAA-2016-3897.

[7] Goodwin, R.V., Fuleki, D., "Turbofan Ice Crystal Rollback Investigation and Preparations Leading to the Second, Heavily Instrumented, Ice Crystal Engine Test at NASA PSL-3 test Facility," 8th AIAA Atmospheric and Space Environments Conference, Washington, D.C, June 13-17, 2016, AIAA-2016-3892.

[8] Veres, J. P., Jorgenson, P. C. E., Jones, S. M, "Modeling of Highly Instrumented Honeywell Turbofan Engine Tested with Ice Crystal Ingestion in the NASA Propulsion System Laboratory," AIAA-2016-3895.

[9] Veres, J. P., Jorgenson, P. C. E., Wright, W. B., Struk, P., “A Model to Assess the Risk of Ice Accretion due to Ice Crystal
Ingestion in a Turbofan Engine and its Effects on Performance," AIAA 2012-3038.

[10] Veres, J. P., Jorgenson, P. C. E., "Modeling Commercial Turbofan Engine Icing Risk with Ice Crystal Ingestion,” AIAA 2013-2679.

[11] Veres, J. P., Jorgenson, P. C. E., Coennen R., "Modeling Commercial Turbofan Engine Icing Risk with Ice Crystal Ingestion; Follow-On," AIAA 2014-2899.

[12] Jorgenson, P. C. E., Veres, J. P., Jones, S. M., "Modeling the Deterioration of Engine and Low Pressure Compressor Performance During a Roll Back Event due to Ice Accretion," AIAA-2014-3842.

[13] Veres, J. P., Jones, S. M., Jorgenson, P. C. E., "Performance Modeling of Honeywell Turbofan Engine Tested with Ice Crystal Ingestion in the NASA Propulsion System Laboratory," SAE2015-01-2133.

[14] Veres, J. P., “Axial and Centrifugal Compressor Mean Line Flow Analysis Method,” AIAA-2009-1641, NASA/TM-2009-215585. 
Table 1

\begin{tabular}{|c|c|c|c|c|c|c|c|c|c|c|c|c|}
\hline PSL & PSL & \begin{tabular}{|l|} 
Calculated \\
\end{tabular} & PSL & PSL & PSL & Calculated & Parametric & \begin{tabular}{|l|} 
Calculated \\
\end{tabular} & Calculated & Calculated & PSL & PSL \\
\hline Escort & Rollback, & Blockage & Altitude & Flight Mach & TWC & Ice-Water /Air & Particle & Melt Ratio & Twbt & Twbs & Anti-Ice & Spinner \\
\hline \multirow[t]{2}{*}{ Data Pt. } & Called, & Growth & Ft. & & Inlet & Flow Ratio & Size $\mu m$ & EGV 2 TE & EGV 2 TE & EGV 2 TE & & Heat \\
\hline & sec & $\mathrm{cm} / \mathrm{sec}$ & & & $g / m^{\wedge} 3$ & IWAR & & & $\mathbf{R}$ & $\mathbf{R}$ & & \\
\hline 235 & 9999 & 0.000066 & 27579.0 & 0.5598 & 1.43 & 0.003120 & 9.500 & 0.0342 & 509.13 & 499.99 & ON & ON \\
\hline 316 & 9999 & 0.000066 & 27964.0 & 0.5587 & 1.17 & 0.002586 & 8.000 & 0.0386 & 507.51 & 498.60 & ON & ON \\
\hline 209 & 360 & 0.001821 & 27710.0 & 0.5532 & 1.36 & 0.002962 & 8.000 & 0.0335 & 507.36 & 498.13 & ON & ON \\
\hline 207 & 9999 & 0.000066 & 27747.9 & 0.5563 & 1.46 & 0.003184 & 7.000 & 0.0383 & 507.56 & \begin{tabular}{l|l}
497.58 \\
\end{tabular} & ON & ON \\
\hline 364 & 115 & 0.005700 & 34093.0 & 0.5571 & 1.34 & 0.003940 & 8.000 & 0.0389 & 506.05 & 497.25 & ON & ON \\
\hline 203 & 111 & 0.005905 & 28437.8 & 0.5532 & 1.44 & 0.003345 & 9.500 & 0.0360 & 504.45 & 497.27 & ON & ON \\
\hline 165 & 80 & 0.008194 & 27775.0 & 0.5048 & 1.36 & 0.002979 & 7.000 & 0.0303 & 506.59 & 496.67 & OFF & OFF \\
\hline 237 & 9999 & 0.000066 & 27882.0 & 0.5559 & 0.71 & 0.001550 & 6.500 & 0.0352 & 505.77 & 496.53 & ON & ON \\
\hline $240 *$ & 470 & 0.001395 & 27860.0 & 0.5547 & 1.43 & 0.003110 & 6.500 & 0.0333 & 505.59 & 496.37 & ON & ON \\
\hline 494 & 9999 & 0.000066 & 27900.0 & 0.5588 & 0.72 & 0.001574 & 6.000 & 0.0396 & 505.48 & 496.30 & OFF & OFF \\
\hline 160 & 33 & 0.019864 & \begin{tabular}{|l|}
28047.0 \\
\end{tabular} & 0.5115 & 3.23 & 0.007116 & 6.000 & 0.0383 & 506.05 & \begin{tabular}{|l|}
496.26 \\
\end{tabular} & OFF & OFF \\
\hline 162 & 35 & 0.018729 & 28028.0 & 0.5098 & 3.23 & 0.007111 & 6.000 & 0.0356 & 505.96 & 496.05 & OFF & OFF \\
\hline 159 & 124 & 0.005286 & 28084.0 & 0.5136 & 1.09 & 0.002408 & 6.000 & 0.0361 & 505.70 & 496.04 & OFF & OFF \\
\hline 200 & 382 & 0.001716 & 28717.0 & 0.5681 & 1.44 & 0.003252 & 6.000 & 0.0362 & 504.93 & 495.95 & ON & ON \\
\hline 293 & 415 & 0.001580 & 27938.0 & 0.5582 & 1.17 & 0.002556 & 6.000 & 0.0343 & 505.18 & 495.90 & ON & ON \\
\hline 295 & 184 & 0.003563 & \begin{tabular}{|l|}
27889.9 \\
\end{tabular} & 0.5554 & 1.44 & 0.003137 & 5.500 & 0.0351 & 505.47 & $\begin{array}{l}495.50 \\
\end{array}$ & ON & ON \\
\hline 205 & 94 & 0.006973 & 27727.0 & 0.5532 & 1.33 & 0.002939 & 6.000 & 0.0367 & 502.85 & 495.12 & ON & ON \\
\hline 301 & 240 & 0.002731 & 27950.0 & 0.5591 & 1.05 & 0.002303 & 4.500 & 0.0346 & 502.57 & 494.05 & ON & ON \\
\hline 285 & 65 & 0.010085 & 34073.0 & 0.5569 & 1.44 & 0.004174 & 4.800 & 0.0349 & 502.94 & 494.01 & ON & ON \\
\hline 285 & 67 & 0.009784 & 34089.4 & 0.558 & 1.44 & 0.004180 & 4.400 & 0.0357 & 503.37 & 493.77 & ON & ON \\
\hline 280 & 73 & 0.008979 & 31060.0 & 0.5611 & 1.43 & 0.003579 & 4.000 & 0.0331 & 502.79 & 493.59 & ON & ON \\
\hline 194 & 85 & 0.007712 & 28482.0 & 0.5564 & 1.41 & 0.003114 & 3.600 & 0.0329 & 502.89 & \begin{tabular}{|l|l|}
493.45 \\
\end{tabular} & ON & ON \\
\hline 227 & 100 & 0.006555 & 28504.0 & 0.5577 & 1.44 & 0.003182 & 3.500 & 0.0348 & 502.90 & 493.44 & ON & ON \\
\hline $464 *$ & 504 & 0.001301 & 32093.0 & 0.5594 & 0.79 & 0.002073 & 3.500 & 0.0394 & 502.47 & 493.30 & ON & ON \\
\hline 229 & 9999 & 0.000066 & 28527.0 & 0.5587 & 0.71 & 0.001570 & 3.200 & 0.0340 & 502.56 & 493.15 & ON & ON \\
\hline 356 & 87 & 0.007534 & 28477.0 & 0.5569 & 1.43 & 0.003152 & 3.200 & 0.0356 & 502.80 & 493.23 & ON & ON \\
\hline 270 & 92 & 0.007125 & 28429.0 & 0.5549 & 1.44 & 0.003171 & 3.200 & 0.0361 & 502.78 & 493.26 & ON & ON \\
\hline 318 & 192 & 0.003414 & 28034.0 & 0.5633 & 1.16 & 0.002502 & 3.100 & 0.0339 & 502.57 & 493.11 & ON & ON \\
\hline 484 & 86 & 0.007622 & 28525.0 & 0.5601 & 1.43 & 0.003159 & 3.200 & 0.0321 & 502.58 & 493.15 & ON & OFF \\
\hline 128 & 61 & $\begin{array}{l}0.010746 \\
\end{array}$ & 28469.0 & 0.5532 & 1.80 & 0.003966 & 3.100 & 0.0360 & 502.70 & 493.22 & ON & ON \\
\hline 124 & 29 & 0.022603 & 28514.1 & 0.5628 & 3.23 & 0.007151 & 3.200 & 0.0385 & 503.90 & 493.45 & ON & ON \\
\hline 178 & 77 & 0.008513 & 28445.0 & 0.5544 & 1.43 & 0.003150 & 3.000 & 0.0351 & 502.70 & 493.11 & ON & ON \\
\hline 150 & 110 & 0.005959 & 28501.0 & 0.5574 & 1.44 & 0.003179 & 3.000 & 0.0318 & 502.82 & 493.01 & OFF & OFF \\
\hline 486 & 95 & 0.006900 & 28475.0 & 0.5569 & 1.43 & 0.003152 & 2.900 & 0.0349 & 502.72 & 493.04 & OFF & OFF \\
\hline 122 & 41 & 0.015988 & 28492.0 & 0.5615 & 1.95 & 0.004312 & 2.900 & 0.0389 & 503.61 & 493.19 & ON & ON \\
\hline 467 & 89 & 0.007365 & 28432.9 & 0.5543 & 1.44 & 0.003171 & 2.710 & 0.0378 & 503.36 & 492.91 & ON & ON \\
\hline 123 & 39 & 0.016808 & 28542.2 & 0.5643 & 2.58 & 0.005716 & 3.000 & 0.0372 & 503.67 & 493.24 & ON & ON \\
\hline 488 & 9999 & 0.000066 & 28480.0 & 0.5569 & 0.71 & 0.001566 & 2.700 & 0.0364 & 502.56 & 492.91 & OFF & OFF \\
\hline 146 & 91 & 0.007203 & 28504.7 & 0.5585 & 1.44 & 0.003177 & 2.660 & 0.0346 & 503.35 & 492.85 & ON & OFF \\
\hline 275 & 102 & 0.006426 & 25932.6 & 0.5589 & 1.44 & 0.002822 & 2.400 & 0.0388 & 503.66 & 492.87 & ON & ON \\
\hline 108 & 120 & 0.005463 & 28489.6 & 0.5564 & 1.42 & 0.003126 & 2.450 & 0.0358 & 503.36 & 492.74 & ON & ON \\
\hline 256 & 180 & 0.003642 & 23815.9 & 0.5512 & 1.43 & 0.002541 & 2.050 & 0.0352 & 503.92 & 492.63 & ON & ON \\
\hline 320 & 123 & 0.005329 & 28001.0 & 0.5607 & 1.17 & 0.002487 & 1.570 & 0.0319 & 502.80 & 492.41 & ON & ON \\
\hline $93 * *$ & 69 & 0.009500 & 28947.0 & 0.5158 & 1.36 & 0.003040 & 1.580 & 0.0372 & 503.45 & 492.30 & ON & ON \\
\hline 462 & 209 & 0.003136 & 32064.0 & 0.5587 & 0.78 & 0.002012 & 1.600 & 0.0348 & 502.38 & 492.33 & ON & ON \\
\hline 406 & 9999 & 0.000066 & 4885.3 & 0.1925 & 3.24 & 0.002699 & 1.200 & 0.0000 & 507.31 & 491.59 & ON & ON \\
\hline 320 & 123 & 0.005329 & 27973.4 & 0.5592 & 1.17 & 0.002484 & 1.390 & 0.0338 & 504.28 & 492.43 & ON & ON \\
\hline 202 & 87 & 0.007534 & 28486.0 & 0.5568 & 1.43 & 0.003109 & 1.500 & 0.0344 & 503.45 & 492.50 & ON & ON \\
\hline 242 & 9999 & 0.000066 & 28894.1 & 0.5571 & 0.71 & 0.001570 & 1.188 & 0.0341 & 504.18 & 492.33 & ON & ON \\
\hline 344 & 186 & 0.003524 & 31035.0 & 0.5578 & 0.90 & 0.002192 & 1.235 & 0.0344 & 503.06 & 492.31 & ON & ON \\
\hline 338 & 268 & 0.002446 & 31033.0 & 0.5588 & 0.92 & 0.002213 & 1.410 & 0.0369 & 504.22 & 492.54 & ON & ON \\
\hline 166 & 454 & 0.001444 & 28013.3 & 0.5089 & 1.01 & 0.002076 & 1.233 & 0.0357 & 511.47 & 491.95 & OFF & OFF \\
\hline 197 & 120 & 0.005463 & 28455.0 & 0.5549 & 1.23 & 0.002737 & 1.300 & 0.0358 & 501.26 & 492.33 & ON & ON \\
\hline 444 & 219 & 0.002993 & 32270.0 & 0.5713 & 0.85 & 0.002183 & 1.160 & 0.0317 & 503.20 & 492.29 & ON & ON \\
\hline 448 & 184 & 0.003563 & 32249.0 & 0.5567 & 0.98 & 0.002510 & 1.130 & 0.0333 & 503.26 & 492.29 & ON & ON \\
\hline 446 & 106 & 0.006184 & 32033.0 & 0.5567 & 1.43 & 0.003632 & 1.200 & 0.0348 & 503.75 & 492.36 & ON & ON \\
\hline 450 & 170 & 0.003856 & 32083.0 & 0.5594 & 1.01 & 0.002566 & 1.080 & 0.0367 & 503.77 & 492.30 & ON & ON \\
\hline
\end{tabular}


Table 1 (continued)

\begin{tabular}{|c|c|c|c|c|c|c|c|c|c|c|c|c|}
\hline PSL & PSL & Calculated & PSL & PSL & PSL & Calculated & \begin{tabular}{|l|} 
Parametric \\
\end{tabular} & Calculated & Calculated & Calculated & PSL & PSL \\
\hline Escort & Rollback, & Blockage & Altitude & Flight Mach & TWC & Ice-Water /Air & Particle & Melt Ratio & Twbt & Twbs & Anti-Ice & Spinner \\
\hline \multirow[t]{2}{*}{ Data Pt. } & Called, & Growth & Ft. & & Inlet & Flow Ratio & Size $\mu m$ & EGV 2 TE & EGV 2 TE & EGV 2 TE & & Heat \\
\hline & sec & $\mathrm{cm} / \mathrm{sec}$ & & & $\mathrm{g} / \mathrm{m}^{\wedge} 3$ & IWAR & & & $\mathbf{R}$ & $\mathbf{R}$ & & \\
\hline 452 & 172 & 0.003811 & 32055.0 & 0.5579 & 1.00 & 0.002538 & 1.010 & 0.0374 & 503.50 & 492.20 & ON & ON \\
\hline 454 & 349 & 0.001878 & 32068.0 & 0.5582 & 0.77 & 0.001955 & 1.026 & 0.0376 & 503.77 & 492.27 & ON & ON \\
\hline 324 & 9999 & 0.000066 & 31034.0 & 0.5582 & 0.77 & 0.001852 & 0.923 & 0.0345 & 504.06 & 492.22 & ON & ON \\
\hline 322 & 154 & 0.004256 & 31091.0 & 0.5614 & 1.16 & 0.002795 & 0.980 & 0.0369 & 504.15 & 492.30 & ON & ON \\
\hline 332 & 285 & 0.002300 & 31046.0 & 0.5588 & 0.85 & 0.002045 & 0.912 & 0.0366 & 504.19 & 492.23 & ON & ON \\
\hline 334 & 180 & 0.003642 & 31041.3 & 0.5594 & 0.84 & 0.002021 & 0.862 & 0.0348 & 505.26 & 492.19 & ON & ON \\
\hline 330 & 363 & 0.001806 & 31100.0 & 0.562 & 0.85 & 0.002047 & 0.835 & 0.0373 & 505.49 & 492.19 & ON & ON \\
\hline 328 & 300 & 0.002185 & 31084.0 & 0.5614 & 0.86 & 0.002070 & 0.845 & 0.0386 & 505.52 & 492.21 & ON & ON \\
\hline 440 & 9999 & 0.000066 & 32066.0 & 0.5169 & 0.58 & 0.001468 & 1.100 & 0.0000 & 493.15 & 483.09 & ON & ON \\
\hline 340 & 9999 & 0.000066 & 31110.0 & 0.5623 & 0.90 & 0.002104 & 1.000 & 0.0000 & 492.53 & 480.95 & ON & ON \\
\hline 506 & 9999 & 0.000066 & 30010.0 & 0.5585 & 1.42 & 0.003138 & 0.900 & 0.0000 & 493.39 & 480.83 & OFF & OFF \\
\hline 504 & 9999 & 0.000066 & 30096.0 & 0.5634 & 0.71 & 0.001570 & 1.000 & 0.0000 & 489.24 & 477.82 & OFF & OFF \\
\hline 458 & 9999 & 0.000066 & 32032.0 & 0.5556 & 0.74 & 0.001926 & 1.450 & 0.0000 & 471.66 & 466.01 & ON & ON \\
\hline
\end{tabular}

Note:

A value of 9999 in the Rollback column above indicates that the data point did not result in a called engine rollback.

* The called rollback time was extrapolated linearly from the last Escort scan before the ice cloud was turned off.

** Full engine rollback data point. However, the engine experienced a 7\% loss of thrust after 69 seconds (at Escort scan 92), after the ice cloud was initiated and could have been a called engine rollback at that time. 